of biological therapies in RA patients. However, being a real-life setting, unknown confounding factors might generate an apparent association or mask a true correlation between the HBcAb status and clinical outcomes.

Disclosure of Interest: None declared

DOI: 10.1136/annrheumdis-2017-eular.2032

\section{SAT0106 FURTHER "WELLNESS" CAN BE ACHIEVED BY SURGICAL INTERVENTION IN THE IMPAIRED HAND EVEN FOR PATIENTS WITH WELL-CONTROLLED RHEUMATOID ARTHRITIS}

H. Ishikawa ${ }^{1}$, A. Abe ${ }^{1}$, Y. Nomura ${ }^{1}$, S. Ito ${ }^{1}$, T. Kojima ${ }^{2}$, M. Kojima ${ }^{3}$, N. Ishiguro ${ }^{2}, A$. Murasawa ${ }^{1} .{ }^{1}$ Rheumatology, Niigata Rheumatic Center, Shibata; ${ }^{2}$ Orthopedic Surgery, Nagoya University Hospital; ${ }^{3}$ Medical Education, Nagoya City University Hospital Graduate School of Medicine, Nagoya, Japan

Background: The hand is the most frequently involved site in rheumatoid arthritis (RA). The treatment aim of RA is achieving and maintaining remission (REM) or low disease activity (LDA) via tight medical control. However, despite remarkable advances in medication, progressive deterioration and/or deformity of the hand, if adequate medication is not administered in the early stage. Surgical reconstruction is still required in hands with functional loss and/or a grotesque appearance caused by joint deterioration or tendon rupture. Recently, patients have expressed a desire to achieve functional REM with a higher quality of life (QOL) and improved mental wellness.

Objectives: The objective of this study was to clarify the systemic effects of surgical intervention in the impaired hand, even in patients with well-controlled disease who have achieved REM or LDA.

Methods: A prospective cohort study was performed in 119 hands of 119 patients with functional loss and/or a grotesque appearance due to RA who underwent primary elective surgery between October 2012 and September 2014. A total of 42 hands in 42 patients (males: 2, females: 40 ) had a disease activity of REM or LDA just before surgery. In the REM/LDA group, the average (range) age was 61 (29-82) years, and the average (range) disease duration was 15 (2-35) years. The procedures performed included Darrach procedure (ulnar head resection) in 17 hands, radiolunate arthrodesis in 10, extensor tendon reconstruction in 6 , thumb/finger metacarpophalangeal joint arthroplasty (Swanson) in 14, proximal interphalangeal (interphalangeal) joint fusion in 4 , and thumb CM joint arthroplasty (Thompson) in 4 and so on. The patient-reported outcome (PRO) was assessed using the Health Assessment Questionnaire-Disability Index (HAQ-DI), EuroQol-5 Dimensions (EQ-5D), Beck Depression Inventory-II (BDI-II), Patient's General Health using visual analogue scale of $100 \mathrm{~mm}$ (Pt-GH), and the Disabilities of the Arm, Shoulder and Hand (DASH). The 28-joint Disease Activity Score using $C$ reactive protein (DAS28-CRP) and Grip power (GP) were also examined. All of these items were investigated just before surgery (baseline) and again at 6 and 12 months after surgery.

Results: On the whole, the physical function (HAQ-DI, DASH, GP), QOL (HAQ-DI, EQ-5D, Pt-GH), mental wellness (BDI-II, Pt-GH), and disease activity (DAS28CRP) were significantly improved at 6 and 12 months after surgery compared to baseline $(p<0.05)^{1}$. In the REM/LDA group, a significant improvement was noted in the upper-extremity function (DASH), QOL (EQ-5D), and disease activity (DAS28-CRP) at 6 and 12 months after surgery; however, we did not observe any significant changes in any other items (Table1).

Table 1: Outcome of surgical intervention in the impaired hand for patients with rheumatoid arthritis

\begin{tabular}{|c|c|c|c|c|c|c|c|c|}
\hline & & HAQ-DI & $E Q \cdot 5 D$ & BDI-II & $\begin{array}{l}\text { Pt-GH } \\
(\mathrm{mm})\end{array}$ & DASH & $\begin{array}{l}\text { GP } \\
(\mathrm{mmHg})\end{array}$ & $\begin{array}{l}\text { DAS28 } \\
\text { CRP }\end{array}$ \\
\hline \multirow{3}{*}{$\begin{array}{l}\text { Total } \\
n=119\end{array}$} & baseline & $\begin{array}{c}1.07 \\
(0.73)\end{array}$ & $\begin{array}{c}0.72 \\
(0.12)\end{array}$ & $\begin{array}{l}13.4 \\
(9.4)\end{array}$ & $\begin{array}{l}35 \\
(23)\end{array}$ & $\begin{array}{c}42.1 \\
(22.5)\end{array}$ & $\begin{array}{l}126 \\
(58)\end{array}$ & $\begin{array}{c}3.1 \\
(0.9)\end{array}$ \\
\hline & $\begin{array}{l}\text { PO\# } \\
\text { 6mos. }\end{array}$ & $\begin{array}{l}0.97^{*} \\
(0.78)\end{array}$ & $\begin{array}{l}0.76^{* *} \\
(0.14)\end{array}$ & $\begin{array}{c}11.7^{* *} \\
(8.6)\end{array}$ & $\begin{array}{l}24^{* *} \\
(21)\end{array}$ & $\begin{array}{l}36.7^{* *} \\
(21.7)\end{array}$ & $\begin{array}{l}135^{*} \\
(55)\end{array}$ & $\begin{array}{l}2.4^{* *} \\
(2.1)\end{array}$ \\
\hline & $\begin{array}{l}\text { PO\# } \\
\text { 12mos }\end{array}$ & $\begin{array}{l}0.91 * * \\
(0.78)\end{array}$ & $\begin{array}{l}0.76^{* *} \\
(0.14)\end{array}$ & $\begin{array}{c}11.9^{* *} \\
(9.1)\end{array}$ & $\begin{array}{l}24^{* *} \\
(20)\end{array}$ & $\begin{array}{l}35.7^{* *} \\
(23.0)\end{array}$ & $\begin{array}{c}139 * * \\
(60)\end{array}$ & $\begin{array}{l}2.2^{2 *} \\
(0.8)\end{array}$ \\
\hline \multirow{3}{*}{$\begin{array}{l}\text { REM+LDA } \\
n=42\end{array}$} & baseline & $\begin{array}{c}0.85 \\
(0.63)\end{array}$ & $\begin{array}{c}0.75 \\
(0.14)\end{array}$ & $\begin{array}{l}11.0 \\
(8.1)\end{array}$ & $\begin{array}{c}15 \\
(13)\end{array}$ & $\begin{array}{c}34.6 \\
(21.8)\end{array}$ & $\begin{array}{l}143 \\
(61)\end{array}$ & $\begin{array}{c}2.1 \\
(0.5)\end{array}$ \\
\hline & $\begin{array}{l}\text { PO\# } \\
\text { 6mos. }\end{array}$ & $\begin{array}{c}0.80 \\
(0.68)\end{array}$ & $\begin{array}{l}0.80^{* *} \\
(0.15)\end{array}$ & $\begin{array}{l}10.1 \\
(8.1)\end{array}$ & $\begin{array}{c}16 \\
\text { (18) }\end{array}$ & $\begin{array}{l}30.2^{* *} \\
(19.6)\end{array}$ & $\begin{array}{l}143 \\
(57)\end{array}$ & $\begin{array}{l}1.8^{* *} \\
(0.6)\end{array}$ \\
\hline & $\begin{array}{l}\text { PO\# } \\
12 \mathrm{mos}\end{array}$ & $\begin{array}{c}0.81 \\
(0.760)\end{array}$ & $\begin{array}{l}0.79 * * \\
(0.16)\end{array}$ & $\begin{array}{l}10.8 \\
(8.3)\end{array}$ & $\begin{array}{c}14 \\
(14)\end{array}$ & $\begin{array}{l}30.1^{* *} \\
(21.0)\end{array}$ & $\begin{array}{l}151 \\
(66)\end{array}$ & $\begin{array}{l}1.8^{* *} \\
(0.7)\end{array}$ \\
\hline
\end{tabular}

Mean(SD) *: $p<0.05$ compared to baseline, $" *: p<0.01$ compared to baseline

Conclusions: Achieving REM or LDA is not the ultimate goal of treatment for patients with functional loss and/or a grotesque appearance of their hands. Further "wellness" can be achieved by surgical intervention in the affected hand, even for patients with well-controlled RA. Such intervention can also ameliorate the disease activity.

References:

[1] Ishikawa H, Murasawa A, Nakazono K, et al. The patient-based outcome of upper-extremity surgeries using the DASH questionnaire and the effect of disease activity of the patients with rheumatoid arthritis. Clin Rheumatol. 2008;27:967-973.

Disclosure of Interest: None declared

DOI: 10.1136/annrheumdis-2017-eular.2850

\section{SAT0107 FACTORS THAT INFLUENCE ON PAIN CONTROL DURING TREATMENT FOR RHEUMATOID ARTHRITIS PATIENT}

I. Yoshii ${ }^{1}$, T. Chijiwa ${ }^{2} .{ }^{1}$ Rheumatology, Yoshii Hospital, Shimanto City; ${ }^{2}$ Rheumatology, Kochi Memorial Hospital, Kochi, Japan

Background: Pain control is the most important theme for treatment of rheumatoid arthritis (RA) patient. For pain control, it is obviously important key to control disease activity control. However, patient status at start of treatment (BL), can be also important as well as disease activity control. Including these factors, keys that can reduce pain should be clarified.

Objectives: In this study, factors that affect on pain control were evaluated statistically from real clinical data.

Methods: In 685 RA patients who have been treated for more than 1 year, 500 patients were monitored their disease activity with parameters in 28-joints disease activity index with C-reactive protein (DAS28-CRP), pain score with using visual analogue scale (PS-VAS), modified Health Assessment Questionnaire Disability Index (mHAQ). Drugs administered for patient had been checked at the time of consult.

PS-VAS at consult was evaluated, as it demonstrated no more than $15 \mathrm{~mm}$, or decrease than last time more than $20 \mathrm{~mm}$ was evaluated as "Pain Reduced". Patients sex, ACP, Sharp/van der Heijde Score (SHS), patients current age, history length, DAS28-CRP and its components, PS-VAS at BL, and followed consultation, drug usage and its dosage were evaluated for Pain Reduced statistically with Binary Logistic Regression Analysis. Significant level was set within $1 \%$.

Results: 14,005 times from 495 patients were enrolled in this study. At BL, male patient, higher ACPA, younger age at onset and at BL, older age at following consultation, short following term, smaller SvdHS, greater tenderness joint count (TJC), swollen joint count (SJC), smaller patient's global assessment (PGA), evaluator's global assessment (EGA), great CRP, and smaller $\mathrm{mHAQ}$ and DAS28-CRP at BL demonstrated significant contribution on Pain Reduce. In following consult, smaller mHAQ, PS-VAS, and DAS28-CRP, in which smaller PGA and EGA, demonstrated significant contribution on Pain Reduce. In drugs, paraetamol/tramadol combination drug use, non-steroid anti-inflammation drug (NSAIDs) use, pregabalin use, tofacitinib use, and opioid use, and methotrexate dose decrease demonstrated significant contribution on Pain Reduce.

Conclusions: These results suggest that pain control for RA patient depends on patient's status at baseline. And followed disease activity control and activity in daily life (ADL) maintenance. In adding with these, drug selection is also important key. It is also suggested specific drugs have higher effect on pain control. Anti-chronic pain agent can be candidate for pain relief for the patient who complains remnant pain even after successful disease activity control and ADL maintenance.

Disclosure of Interest: None declared

DOI: 10.1136/annrheumdis-2017-eular.4213

\section{SAT0108 CLINICAL SIGNIFICANCE OF ANTI-ACTIN ANTIBODIES IN AUTOIMMUNE INFLAMMATORY RHEUMATIC DISEASES}

I. Ayadi, L. Laadhar, M. Kallel-Sellami. Immunology, la Rabta Hospital, Tunis, Tunisia

Background: Anti-actin antibodies (AAA) are well-described as the major component of smooth muscle autoantibodies (microfilament antibodies). They are specially detected in patients with chronic active hepatitis $(\mathrm{CAH})$ and celiac disease (CD). AAA have also been found less frequently in various other autoimmune disorders including systemic lupus erythematosus (SLE), Sjogren's syndrome, and myasthenia gravis, as well as in primary biliary cirrhosis and alcoholic liver disease.

Objectives: to study clinicobiological characteristics of patients with AAA in autoimmune inflammatory rheumatic diseases (AIRD).

Methods: From January to December 2016, we have collected all cases of patients with AAA presenting for symtomatology of AIRD. The presence of AAA was detected fortuitously by indirect immunofluorescence (IIF) in accordance with its characteristic fluorescence pattern in HEp2 cells (BioRad ${ }^{\odot}$ ). The specificity for F-actin was confirmed by IIF on rat liver-kidney-stomach sections (Biosystem ${ }^{\circledR}$ ) and/or Immunodot $\left(\right.$ Euroimmun $\left.^{\circledR}\right)$. Coeliac disease related antibodies were performed in all patients with AAA.

Results: Six patients were included: 5 women and a man with a mean age of 43.5 years. AIRD have been suspected in these patients and the mean clinical features were inflammatory polyarthralgia and fever. AIRD was diagnosed in three cases: One patient presented with SLE and two others with rheumatoid arthritis (RA). Hepatic function was disturbed with elevated serum ALT and AST activities in one case higly suspected of $C A H$. CD was diagnosed in one case. The sixth patient had positive antinuclear antibodies, hypocomplementemia and anti-Ro52, anti-SSB and anti-DFS antibodies associated with FR but didn't 
fulfilled SLE criteria. The immunological tests showed anti-nuclear antibodies among all patients with high titre and anti-DNA antibodies in SLE and CAH patients respectively. One RA patient had anti-Ro60 antibodies.

Conclusions: During our study, AAA were found fortuitously in AIRD. This association is rarely described in the literature. Hepatic involvement can be seen during AIRD. Nevertheless, a CAH and CD associated shouldn't be disregarded. References:

[1] Diagnostic value of anti-actin antibodies in a French multicenter study. P.Chretien-Leprince et al; Ann N Y Acad Sci. 2005;1050:266-73.

[2] Smooth-muscle antibodies in rheumatoid arthritis. I.Andresen et al; Acta Pathol. Microbiol. Scand. 1980;88: 131-135.

Disclosure of Interest: None declared

DOI: 10.1136/annrheumdis-2017-eular.6748

\section{SAT0109 QUANTITATIVE ESTIMATES OF DAMAGE AND DISTRESS, IN ADDITION TO INFLAMMATION, AND THE PROPORTION EACH OF THE 3 VARIABLES AFFECTS CLINICAL MANAGEMENT DECISIONS (TOTAL=100\%) MAY CLARIFY ASSESSMENT OF CLINICAL STATUS IN PATIENTS WITH RHEUMATOID ARTHRITIS (RA)}

K.A. Gibson ${ }^{1,2,3}$, I. Castrejon ${ }^{4}$, T. Pincus ${ }^{4} .{ }^{1}$ Rheumatology, Liverpool Hospital; ${ }^{2}$ ingham Research Institute, Liverpool; ${ }^{3}$ University of New South Wales, Sydney, Australia; ${ }^{4}$ Rheumatology, Rush University Medical Center, Chicago, United States

Background: Quantitative assessment in rheumatoid arthritis (RA) is directed to inflammatory activity (INF) and not to joint damage (DAM) and distress (STR seen as fibromyalgia, depression, etc.). However, DAM and STR may affect clinical management and outcomes of treatment in many RA patients. For example, an RA patient with well-controlled INF who has secondary fibromyalgia may have 0 swollen joints (SJC) and an ESR $\geq$ of 15 , but nonetheless have a DAS28 of 5.1, CDAI of $\geq 22$, and RAPID3 of $\geq 16$ (indicating high activity), based on 14/28 tender joints and a patient global assessment of 80/100. Therefore, quantitative estimates of DAM, and STR, as well as INF may clarify patient status and clinical management decisions.

Objectives: To analyze physician quantitative estimates for the proportion of management decisions attributed to INF, DAM, or STR (total=100\%) in RA patients seen in routine care.

Methods: At one academic rheumatology center, the rheumatologist completes four 0-10 visual analog scales (VAS) for overall global assessment (DOCGL), INF, DAM, and STR. In patients with DOCGL $\geq 2$, the proportion of management decisions are estimated as $\% \mathrm{INF}+\% \mathrm{DAM}+\% \mathrm{STR}=100 \%$. Cross-tabulations were computed for various phenotypes in $5 \mathrm{INF}+\mathrm{DAM}$ and INF+STR categories, 0 , $1-20 \%, 21-40 \%, 42-60 \%$, and $61-100 \%$.

Results: Among the 77 RA patients, $>40 \%$ of clinical management decisions were attributed to INF in only $31(40 \%)$, versus $>40 \%$ to DAM in $33(43 \%)$, and $>40 \%$ to STR in $17(22 \%)$ (Table). No category of INF+DAM or INF+STR included more than $20 \%$ of the patients, and patients were found in 17 of 25 possible categories for combinations of INF+DAM and INF+STR. The 13 patients (17\%) in whom INF was estimated to contribute $0 \%$ to management included 3 of 5 DAM and 5 of 5 STR categories (Table). The 23 patients with $1-20 \%$ of management attributed to INF included 4/5 DAM and 5/5 STR categories. The 10 with $21-40 \%$ INF included 4/5 DAM and 4 STR categories. The 16 with $41-60 \%$ attributed to INF included 3 DAM and 2 STR categories. Only 15 of the 77 patients (19\%) had $>60 \%$ attributed to INF.

Number among 77 RA patients with physician estimates of $\%$ inflammation, $\%$ damage and $\%$ distress (total $=100 \%$ ) in clinical management decisions ( $\%$ is of all patients)

\begin{tabular}{lcccccc}
\hline \% Inflammation: & 0 & $1-20 \%$ & $21-40 \%$ & $41-60 \%$ & $61-100 \%$ & Total \\
$\mathrm{N}$ & $13(17 \%)$ & $23(30 \%)$ & $10(13 \%)$ & $16(21 \%)$ & $15(19 \%)$ & 77 \\
\hline$\%$ Damage: & & & & & & \\
$0-20 \%$ & $3(4 \%)$ & $8(10 \%)$ & $5(6 \%)$ & $3(4 \%)$ & $14(18 \%)$ & $33(43 \%)$ \\
$21-40 \%$ & 0 & 0 & $2(3 \%)$ & $8(10 \%)$ & $1(1 \%)$ & $11(14 \%)$ \\
$41-60 \%$ & $3(4 \%)$ & $4(5 \%)$ & $1(1 \%)$ & $5(6 \%)$ & 0 & $13(17 \%)$ \\
$61-80 \%$ & 0 & $6(8 \%)$ & $2(3 \%)$ & 0 & 0 & $8(10 \%)$ \\
$81-100 \%$ & $7(9 \%)$ & $5(6 \%)$ & 0 & 0 & 0 & $12(16 \%)$ \\
$\%$ Distress: & & & & & & \\
$0-20 \%$ & $7(9 \%)$ & $13(17 \%)$ & $3(4 \%)$ & $15(19 \%)$ & $15(19 \%)$ & $53(69 \%)$ \\
$21-40 \%$ & $1(1 \%)$ & $2(3 \%)$ & $3(4 \%)$ & $1(1 \%)$ & 0 & $7(9 \%)$ \\
$41-60 \%$ & $2(3 \%)$ & $2(3 \%)$ & $2(3 \%)$ & 0 & 0 & $6(8 \%)$ \\
$61-80 \%$ & $1(1 \%)$ & $4(5 \%)$ & $2(3 \%)$ & 0 & 0 & $7(9 \%)$ \\
$81-100 \%$ & $2(3 \%)$ & $2(3 \%)$ & 0 & 0 & 0 & $4(5 \%)$ \\
\hline
\end{tabular}

Conclusions: Quantitative physician estimates of the proportion of clinical management decisions attributed INF, DAM, and STR may help clarify RA patient status and document a basis for clinical decisions. High levels of DAM and/or STR may explain in part why a target of RA remission often is not met in many patients seen in routine clinical care.

References:

[1] Tymms et al, Arth Care \& Res 66:190-196, 2014.

Disclosure of Interest: K. Gibson: None declared, I. Castrejon: None declared, T. Pincus Shareholder of: Health Report Services, Inc

DOI: 10.1136/annrheumdis-2017-eular.6239

\section{SAT0110 THE IMPACT OF PUMMONARY INVOLVEMENT TO THE TREATMENT OF REUMATOID ARTHRITIS}

K. Setoguchi ${ }^{1}$, F.Y. Chen ${ }^{1}$, S. Kamei ${ }^{1}$, M. Ogawa ${ }^{1}$, S. Kobayashi ${ }^{2} .{ }^{1}$ Systemic immunological diseases, Tokyo metropolitan Komagome Hospital; ${ }^{2}$ Allergy and Rheumatology, Graduate school of medicine, The University of Tokyo, Tokyo, Japan

Background: Standard treatment of patients with rheumatoid arthritis (RA) complicated with pulmonary involvements has not been clarified.

Objectives: To evaluate the influence of pulmonary involvement on immunological background and treatment of patients with RA

Methods: A cross-sectional study was conducted, in which medical records of 479 RA patients who visited our hospital during September the first to November 31th, 2016 were reviewed. Pulmonary involvements were diagnosed by imaging including plain chest radiography or chest computed tomography findings. Patients were divided into two groups, with or without pulmonary involvement, and compared with immunological background (serum level of rheumatoid factor (RF), anti-CCP antibody and recent treatment.

Results: Among 479 patients, pulmonary involvements were diagnosed in 158 patients (female $=116$ ), mean age was 73.4 (standard deviation (SD) 9.0) year old, and mean disease duration was 143.3 (SD 125.9) months. Pulmonary involvements included interstitial pneumonia $(\mathrm{N}=52)$, organizing pneumonia $(\mathrm{N}=11)$, airway diseases $(\mathrm{N}=36)$, old tuberculosis $(\mathrm{N}=18)$, nontuberculous mycobacteria $(\mathrm{N}=13)$, pleurisy $(\mathrm{N}=5)$. Higher anti-CCP titers were found in RA with pulmonary involvement than $R A$ only (medians $303.9 \pm 596.5$ versus $163.5 \pm 256.1 \mathrm{U} / \mathrm{mL}$, $P<0.001$ ), and the same result was found in RF (medians $322.5 \pm 437.2$ versus $157.9 \pm 277.5 \mathrm{IU} / \mathrm{mL}, \mathrm{P}<0.001)$. Methotrexate $(\mathrm{MTX})$ was less frequently used $(\mathrm{N}=56,35.4 \%$ versus $\mathrm{N}=205,63.9 \%, \mathrm{P}<0.001)$, but biological agents were more used $(\mathrm{N}=31,19.6 \%$ versus $\mathrm{N}=49,15.3 \%)$, especially abatacept (ABT) was highly used $(\mathrm{N}=15,9.5 \%$ versus $\mathrm{N}=8,2.5 \%)$

Conclusions: RA patients with pulmonary involvements had high immunological response and were less prescribed MTX with may injure lungs and more used ABT. Association between pulmonary involvement and high titer of ACPA, and between positivity for RF or ACPA and good response of ABT were reported. ABT may be useful treatment for RA patients with pulmonary involvement.

References:

[1] Gottenberg JE et al.: Arthritis Rheumatol.68 (6):1346-1352.2016.

[2] Rocha-Munoz AD et al.: J immunol Res. Epub 2015 May 19.

Disclosure of Interest: None declared

DOI: 10.1136/annrheumdis-2017-eular.3936

\section{SAT0111 CLARA CELL PROTEIN CC16 AND ITS PATHOGENIC ROLE IN BRONCHIAL OBSTRUCTION IN PATIENTS WITH RHEUMATOID ARTHRITIS}

K.V. Nochevnaya ${ }^{1}$, I.I. Nesterovich ${ }^{2}$, Y.D. Rabik ${ }^{2}$, A.A. Speranskaya ${ }^{3}$, V.P. Zolotnitskaya ${ }^{3}$, N.A. Amosova ${ }^{3}$, V.I. Amosov ${ }^{3}$, V.I. Trofimov ${ }^{2}$, T.D. Vlasov ${ }^{4}$ ${ }^{1}$ Hospital Therapy Department, Department of Pathophysiology; ${ }^{2}$ Hospital Therapy Department; ${ }^{3}$ Radiology Department; ${ }^{4}$ Department of Pathophysiology, Academician I.P. Pavlov First St. Petersburg State Medical University, Saint Petersburg, Russian Federation

Background: Bronchial obstruction (BO) is a common manifestation of lung involvement in rheumatoid arthritis (RA) with high incidence from 60 to $80 \%$ of all cases. However the pathogenesis of $\mathrm{BO}$ in patients with RA remains unknown. Serum level of protein CC16 produced by Clara cells in terminal bronchioles has been reported to decrease in BO associated with bronchial asthma, chronic obstructive pulmonary disease and others. CC16 was considered to demonstrate anti-inflammatory effect via inhibition of interferon-gamma, tumor necrosis factor alpha, interleukin 1 beta, neutrophil elastase and other proinflammatory factors Also it was shown that $\mathrm{CC} 16$ deficiency has a pathogenic effect in BO. In the same time the role of protein $\mathrm{CC} 16$ in the pathogenesis of autoimmune diseases (and RA) is not studied.

Objectives: We aimed to evaluate serum level of CC16 in patients with RA in dependence on the presence and severity of $\mathrm{BO}$.

Methods: Serum levels of CC16 in 66 patients with RA and 13 healthy controls were measured by enzyme linked immunoadsorbent assay (ELISA). Patients with RA underwent survey, physical examination and pulmonary function tests (PFTs) including spirometry and bronchodilator test with inhalation of salbutamol $(\mathrm{N}=41)$ and body plethysmography $(\mathrm{N}=11)$. Statistical processing was carried out using Spearman correlation coefficient and Mann-Whitney test. $P$ value $<0.05$ was considered as significant.

Results: More than $60 \%$ of participants with RA had BO in terminal bronchioles (small airway obstruction), which was revealed with changes of expiratory flows (forced expiratory volume in 1s (FEV1), forced expiratory flow (FEF) between $50 \%$ and $75 \%$ of forced vital capacity), residual volume (RV) and bronchial resistance (SGaw) in relation to proper values. Depression of post-bronchodilator $\mathrm{FEF}_{75 \%}$ lower than $70 \%$ was adopted as the main criterion of $\mathrm{BO}$. There were no differences ( $p$ value $>0,05$ ) between serum levels of CC16 in patients with RA $(20,14 \pm 1,49 \mathrm{ng} / \mathrm{ml})$ and control group $(22,70 \pm 2,13 \mathrm{ng} / \mathrm{ml})$. However in patient group those with $\mathrm{BO}$ had significantly lower levels of CC16 $(15,59 \pm 1,89$ compared with $27,43 \pm 2,81$ in patients without $\mathrm{BO}, \mathrm{p}$ value $<0,01)$. Lower $\mathrm{CC} 16$ was associated with decreased post-bronchodilator FEV1 and $\mathrm{FEF}_{75 \%}(r=0,345, p$ 